\title{
Distribuição geoquímica e biodisponibilidade de metais traço em sedimentos no Rio Bento Gomes, Poconé - MT, Brasil
}

\author{
Josias do Espírito Santo CORINGA ${ }^{1 *}$, Leonardo PEZZA², Elaine de Arruda Oliveira CORINGA³, \\ Oscarlina Lucia dos Santos WEBER ${ }^{4}$ \\ 1 Instituto Federal de Mato Grosso - campus Cuiabá Bela vista. Av. Juliano Costa Marques, s/n. 78050-560. Cuiabá - MT \\ 2 Instituto de Química - Universidade Estadual Paulista "Júlio de Mesquita Filho" - Rua Prof. Francisco Degni, 55 Bairro: Quitandinha. 14800-060 - Araraquara, SP. \\ 3 Instituto Federal de Mato Grosso -campus Cuiabá Bela vista. Av. Juliano Costa Marques, s/n. 78050-560. Cuiabá - MT \\ ${ }^{4}$ Universidade Federal de Mato Grosso. Av. Fernando Corrêa da Costa, nº 2367 - Bairro Boa Esperança. 78060-900. Cuiabá - MT \\ * Autor correspondente: josias.coringa@ifmt.edu.br
}

\section{RESUMO}

O sedimento é um dos compartimentos mais importantes dos ecossistemas aquáticos, possui papel importante no transporte e acumulação de metais. Este estudo teve por objetivo determinar a concentração de metais nas frações geoquímicas de sedimentos do Rio Bento Gomes, Pantanal de Poconé (MT) por meio da extração seletiva e sequencial, a fim de avaliar a distribuição e mobilidade dos metais. Os sedimentos foram coletados nos períodos seco e chuvoso em oito pontos distintos, e os metais ( $\mathrm{Fe}$, $\mathrm{Mn}, \mathrm{Cr}, \mathrm{Cu}, \mathrm{Zn}$ e Ni) extraídos dos sedimentos por procedimentos de extração sequencial (baseada no protocolo proposto por BCR - Community Bureau of Reference) e de extraçáo seletiva (baseada no protocolo 3050B da Environmental Protection Agency of the United States), utilizando-se materiais de referência certificados para validação do método analítico. Todos os metais apresentaram teores abaixo do limite previsto na Resolução CONAMA no 454/2012 no período seco, com exceçáo do $\mathrm{Ni}$ no período chuvoso (maior que $18 \mathrm{mg} \mathrm{kg}^{-1}$ ). Os estudos de fracionamento indicaram que os metais foram encontrados nas fraçóes mobilizáveis do sedimento, especialmente associados aos óxidos de ferro. Os metais mais móveis e, consequentemente, mais biodisponíveis, foram o manganês, zinco e níquel, principalmente na época chuvosa. Maiores teores de cobre foram encontrados nas fraçóes residuais do sedimento, indicando baixa mobilidade no meio aquático. A sequência de mobilidade dos metais estudados foi $\mathrm{Mn}>\mathrm{Zn}>\mathrm{Ni}>\mathrm{Cr}>\mathrm{Cu}>\mathrm{Fe}$.

PALAVRAS-CHAVE: Recursos hídricos, áreas úmidas, extração sequencial.

\section{Geochemical distribution and bioavailability of trace metals in sediments of the Bento Gomes River, Poconé - MT, Brazil}

\begin{abstract}
The sediment is one of the major compartments of aquatic ecosystems, it plays an important role in the transport and accumulation of metal. This study aimed to determine the concentration of metals in geochemical fractions of the Bento Gomes River sediments, Pantanal of Poconé (MT) through selective extraction and sequential in order to assess the distribution and mobility of metals. The sediments were collected in the rainy and dry seasons in eight different points, and the metals ( $\mathrm{Fe}, \mathrm{Mn}$, $\mathrm{Cr}, \mathrm{Cu}, \mathrm{Zn}$ and $\mathrm{Ni}$ ) extracted from sediments by sequential extraction procedures (based on the proposed by BCR protocol - Community Bureau of Reference) and selective extraction (based on the 3050B protocol of the Environmental Protection Agency of the United States), using certified reference materials for validation of the analytical method. All metals showed levels below the limits established by CONAMA Resolution no 454/2012 in the dry season, except for Ni in the rainy season (greater than $18 \mathrm{mg} \mathrm{kg}^{-1}$ ). The fractionation studies indicated that the metals were found in mobilized sediment fractions, especially associated with the iron oxides. The metals more mobile and hence more bioavailable, have been manganese, zinc and nickel, particularly in the rainy season. Largest copper contents were found in the residual fraction of the sediment, indicating low mobility in the aquatic environment. The sequence of mobility of the metals studied was $\mathrm{Mn}>\mathrm{Zn}>\mathrm{Ni}>\mathrm{Cr}>\mathrm{Cu}>\mathrm{Fe}$.
\end{abstract}

KEYWORDS: Water resources, wetlands, sequential extraction. 


\section{INTRODUÇÃO}

O Pantanal é uma das maiores extensões de áreas alagáveis do mundo, e geograficamente situa-se entre os biomas Amazônia, Chaco, Cerrado, Mata Atlântica e o Bosque Seco Chiquitano (Ab'Saber 1988). Baseado na heterogeneidade de paisagens e na intensidade e duração da inundação, o Pantanal foi dividido em 11 sub-regiôes, e uma delas é o Pantanal de Poconé. Atualmente, a principal atividade predominante na região é a pecuária, embora a atividade garimpeira para extração de ouro tenha impulsionado a economia local e regional em seus diversos ciclos (Silva 1999). Dentre os impactos ambientais dessa atividade está a contaminação de solos, água e sedimentos de rios por metais traço, especialmente o mercúrio.

Dessa forma, estudos de especiação de metais em ambientes naturais como o Pantanal e a Amazônia são importantes, uma vez em que se busca saber a real situação do ambiente conservativo em face às crescentes intervençôes antrópicas no meio.

Dentre todos os principais impactos que ameaçam os ecossistemas, os metais e metalóides desempenham um papel muito importante devido à sua não degradabilidade, bioconcentração e biomagnificação (Zhang et al. 2012; Townsend et al. 2013; Ye et al. 2015).

Os sedimentos atuam no transporte e acumulação de metais, e por isso são utilizados na determinação das suas fontes e formas de dispersão em sistemas aquáticos (Hortellani et al. 2008; Oliveira et al. 2011). Os metais associados aos sedimentos podem ser liberados na coluna d'água e/ou acumular em plantas e animais, entrando assim na cadeia alimentar (Davutluoglu et al. 2011). Entretanto, fatores ambientais como variaçóes de $\mathrm{pH}$, potencial redox, presença de matéria orgânica podem influenciar na capacidade de estocagem dos sedimentos ou na disponibilidade dos elementos estocados, mobilizando-os no ambiente, principalmente durante os períodos de inundaçáo (Loureiro et al. 2012).

A toxicidade e a mobilidade dos metais e metaloides em sedimentos dependem não só da sua concentração total, mas também da sua forma química específica. A especiação de metais potencialmente tóxicos fornece informaçóes importantes para avaliar a toxicidade e o risco ecológico aos humanos e animais (Ye et al. 2015). Assim, os metais podem se apresentar nas diferentes formas químicas: solúvel, trocável, ligados à matéria orgânica, ligados aos óxidos/hidróxidos de ferro, alumínio e manganês, carbonatos, fosfatos, sulfatos (ou outros minerais secundários), ou ligados aos silicatos (Devesa-Rey et al. 2010). Algumas dessas formas químicas podem estar contribuindo para biodisponibilidade do metal no ambiente aquático, pois apresentam diferentes atividades, toxicidade e mobilizaçáo no meio (Zheng et al. 2013; Ye et al. 2015).
A dinâmica entre as diferentes fraçóes geoquímicas é o alicerce fundamental para o entendimento da biodisponibilidade e facilidade de liberação dos metais no meio, contribuindo para a avaliação ambiental. Daí a importância de determinar náo somente seu teor total, mas sua concentração nas fraçóes geoquímicas do solo ou do sedimento (Karbassi et al. 2010). Para a quantificação dos metais nessas fraçóes podem ser empregadas técnicas de extração utilizando reagentes específicos (Santos et al. 2013) em esquemas de extração simples e sequenciais (Sahuquillo et al. 1999).

A extração sequencial é um método se baseia no uso racional de uma série de reagentes selecionados para solubilizar sucessivamente as diferentes fraçôes químicas e mineralógicas do solo/sedimento, responsáveis por reterem a maior parte dos elementos metálicos no ambiente (Gleyzes et al. 2002). Esse método simula as várias modificações naturais e antropogênicas possíveis nas condiçôes ambientais em que a fase sólida está inserida (Förstner 1995; Martins et al. 2013).

O método de extração sequencial BCR solubiliza os metais em quatro fraçóes: trocável e ligado a carbonatos; ligado aos óxidos de $\mathrm{Fe}-\mathrm{Mn}$; ligado à matéria orgânica e metal fixado na fração residual, os metais remanescentes no sedimento após as extraçóes anteriores são geralmente estáveis, não sendo disponibilizados no ambiente (Velimirović et al. 2011). No presente estudo, este método foi selecionado devido à boa reprodutibilidade e recuperação (Pueyo et al. 2008, Davutluoglu et al. 2011). Esta pesquisa teve por objetivo determinar a concentração dos metais Fe, Mn, Zn, Cr, Cu e Ni nas fraçóes geoquímicas de sedimentos do Rio Bento Gomes, no Pantanal de Poconé, Mato Grosso, por meio da extração seletiva pseudo-total sequencial, a fim de avaliar a distribuiçáo e a mobilidade dos metais potencialmente tóxicos em função das condiçôes ambientais do meio aquático.

\section{MATERIAL E MÉTODOS}

\section{Área de estudo}

Este estudo foi realizado no Pantanal de Poconé, sub-região do Pantanal norte mato-grossense, na bacia hidrográfica do Rio Bento Gomes, dreno coletor principal das microbacias onde se localizam os garimpos de ouro do município de Poconé.

O Pantanal mato-grossense possui um dos maiores sistemas de áreas alagáveis e considerada a maior planície neotropical inundável do mundo (Machado et al. 2012), dividido em onze sub-regióes, definidas com base nos critérios de regime hídrico, relevo, fitofisionomias e textura do solo (Sousa e Souza 2012). A regiáo de Poconé encontra-se representada pela sequência metassedimentar detrítica do Grupo Cuiabá, composta por filitos sericíticos, grafitosos e piritosos, quartzitos micáceos e ferruginosos e 
metaconglomerados, onde ocorre solos lateríticos recobrindo as rochas do Grupo Cuiabá. Possui vegetação típica de cerrado denso, e nas áreas periodicamente inundáveis e de relevo plano desenvolve-se vegetaçáo de Savana Estépica, predominantemente gramíneas (Pereira Filho 1995).

A sub-região do Pantanal de Poconé cobre $11 \%$ do Pantanal brasileiro, com uma área de $17.945 \mathrm{Km}^{2}$, caracterizada por períodos de inundação entre dezembro e maio e de seca entre junho e novembro (Fernandes 2010). O clima é do tipo tropical, com precipitação média anual variando entre 800 a $1.200 \mathrm{~mm}$.

Várias sub-bacias drenam para o Rio Paraguai, entre elas a do Rio Bento Gomes, que engloba os municípios de Poconé e Nossa Senhora do Livramento. Esse manancial nasce a sudeste da cidade de Cuiabá, nas encostas da Serra Descida do Buriti, cuja nascente está situada na Fazenda Fortaleza, localizada a 56036' W e 15045' S, no município de Nossa Senhora do Livramento, no Estado de Mato Grosso (Brasil 1982). O Rio Bento Gomes constitui a principal depositário da drenagem da região, pois recebe o aporte do material transportado pelas drenagens tributárias, e por isso constituise no principal objeto de avaliação ambiental deste estudo.

\section{Amostragem}

O ponto de partida para coleta das amostras foi nas dependências do Instituto Federal de Mato Grosso, no Núcleo de Estudos Avançados do Pantanal (NAPAN), a aproximadamente $10 \mathrm{Km}$ do centro de Poconé, onde o rio Bento Gomes passa ao fundo. As coordenadas geográficas do campus nas margens do rio apresentam latitude $16^{\circ} 19^{\prime} 22,5^{\prime \prime}$ ao sul e longitude $56^{\circ} 32^{\prime} 41,5^{\prime \prime}$ a oeste, em uma altitude de 140 metros.

Foram selecionados oito pontos para a coleta do sedimento (Figura1, Tabela 1) após planejamento prévio e estudo da área, que abrangeu o cruzamento do Rio Bento Gomes com a Estrada Parque Poconé-Porto Cercado (rodovia MT-370). Estes locais de amostragem foram selecionados por estarem localizados em áreas consideradas menos afetadas pela contínua atividade de dragagem e material depositado no leito do rio.

Como o presente trabalho tem por objetivo determinar o teor de metais associados ao sedimento nas suas formas químicas e não mineralógicas, no entendimento dos autores não foi necessária a determinação da associação faciológica das amostras e os processos sedimentares envolvidos em sua gênese e evolução. Dessa forma, os pontos de amostragem foram selecionados a fim de permitir avaliar as contribuiçóes da poluição pontual e difusa no rio, onde: no ponto $\mathrm{P} 1$, área não inundada, permite avaliar a ocorrência de metais em ambiente oxídico, onde o leito de sedimento permanece seco na época de vazante no Pantanal; no ponto P2, localizado perto de uma fazenda de gado, permite examinar os possíveis efeitos das águas de drenagem do solo agrícola na dispersão de metais no sedimento do rio; nos pontos $\mathrm{P} 3$ a P6, o canal principal apresenta mudanças nas condiçôes hidráulicas, ora com sinuosidade, ora com áreas de remanso; no ponto P7, a contribuição da atividade antrópica frequente na região, que altera as condições físico-químicas da água e do sedimento; no ponto $\mathrm{P} 8$, próximo à área urbana, permite avaliar a contribuição da poluição difusa e pontual por esgoto doméstico e águas pluviais.

\section{Coleta das amostras de sedimento}

A coleta do sedimento foi realizada nos períodos seco (agosto) e chuvoso (abril). Foram coletados aproximadamente $2 \mathrm{~kg}$ de sedimento (em triplicata) a 2 metros de profundidade do leito do rio, em locais de baixa energia fluvial, de acordo com as recomendaçôes do USGS (Shelton 1994), utilizando um amostrador Van-Veen, totalizando 24 amostras por período sazonal. Durante a coleta, as amostras foram identificadas e georreferenciadas por meio do Sistema de

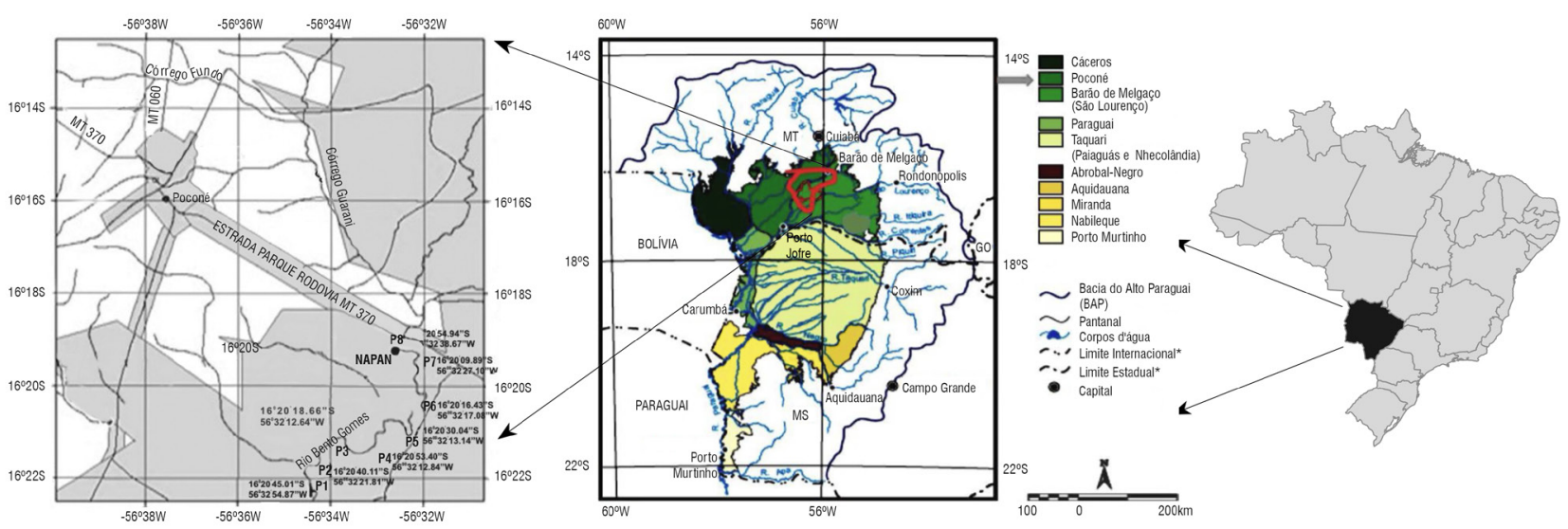

Figura 1. Localização dos pontos de coleta do sedimento ao longo do Rio Bento Gomes, em Poconé, MT, Brasil. 
Tabela 1. Características e localização dos pontos de coleta das amostras de sedimentos do Rio Bento Gomes.

\begin{tabular}{|c|c|c|c|}
\hline \multirow[b]{2}{*}{ Pontos de coleta } & \multirow[b]{2}{*}{ Características do local } & \multicolumn{2}{|c|}{ Coordenadas geográficas } \\
\hline & & Latitude & Longitude \\
\hline P1 & Área não inundada, coletada em leito de sedimento seco. & $16^{0} 20^{\prime} 45.01^{\prime \prime}$ & $56^{0} 3254.87 "$ \\
\hline P2 & Área em frente a uma fazenda de gado, coletada a $3 \mathrm{~m}$ da margem do rio. & $16^{0} 20^{\prime} 40.11^{\prime \prime}$ & $56^{0} 3221.81^{\prime \prime}$ \\
\hline P3 & Área de remanso, com vegetação de aguapé. & $16^{0} 20^{\prime} 18.66^{\prime \prime}$ & $56^{0} 32^{\prime} 12.64 "$ \\
\hline P4 & Pequena ilha formada na curva do rio. & $16^{0} 20^{\prime} 53.40^{\prime \prime}$ & $56^{0} 3212.84 "$ \\
\hline P5 & Área de remanso próximo ao campus do IFMT. & $16^{0} 20^{\prime} 30.04^{\prime \prime}$ & $56032 ' 13.14 "$ \\
\hline P6 & Área de remanso, com vegetação densa no entorno. & $16^{0} 20^{\prime} 16.43^{\prime \prime}$ & $5603217.08 "$ \\
\hline P7 & $\begin{array}{l}\text { Área de remanso com profundidade média de } 7 \text { metros - antiga área de exploração de } \\
\text { areia. }\end{array}$ & $16^{0} 20^{\prime} 09.89 "$ & $5603227.10^{\prime \prime}$ \\
\hline P8 & Área à jusante da ponte próxima à captação da água da cidade (margem oposta). & $16^{0} 20^{\prime} 54.94 "$ & $56^{0} 3238.67^{\prime \prime}$ \\
\hline
\end{tabular}

Posicionamento Global (GPS) (Garmin, eTrex30, Kansas, USA) e acondicionadas em sacos plásticos herméticos, conservados sob refrigeração $\left(4^{\circ} \mathrm{C}\right)$ até o momento da análise.

\section{Análises laboratoriais}

As análises granulométricas e químicas de caracterização do sedimento foram: granulometrica (método da pipeta que consiste na dispersão $\mathrm{NaOH} 0,5 \mathrm{~mol} \mathrm{~L}^{-1}$, agitação por 16 hs e obtenção das frações silte+argila ), pH em água na relação 1:2,5 pelo método potenciométrico , teor de carbono orgânico total (COT) segundo Yeomans e Bremmer (1988) que consistiu na digestão a quente com solução de dicromato de potássio e titulaçáo com sulfato ferroso amoniacal. As analises foram realizadas no Laboratório de Solos da Faculdade de Agronomia e Medicina Veterinária da Universidade Federal de Mato Grosso (UFMT).

Para as análises de fracionamento, as amostras de sedimento foram secas em estufa de circulação de ar a $45^{\circ} \mathrm{C}$ e em seguida peneiradas em malha de nylon com abertura de $0,053 \mathrm{~mm}$.

Os metais (Fe, Mn, $\mathrm{Zn}, \mathrm{Cr}, \mathrm{Cu}$ e $\mathrm{Ni}$ ) foram extraídos da fração fina dos sedimentos por dois métodos:

Extração pelo método 3050B da Environmental Protection Agency of the United States (USEPA 2007): obtém-se a concentração pseudo-total ou biodisponível dos metais, definida como a fração dos metais fracamente ligados à fase sólida, excluindo-se os metais ligados aos minerais. Consiste na digestão da amostra de sedimento com $\mathrm{HNO}_{3} / \mathrm{H}_{2} \mathrm{O}_{2} \mathrm{em}$ bloco digestor a $95 \pm 5^{\circ} \mathrm{C}$ por duas horas (por duas vezes). Os extratos foram diluídos, filtrados e armazenados em frascos de polietileno, conservados a $4^{\circ} \mathrm{C}$ até a determinação dos metais;

Extração sequencial pelo método BCR do European Community Bureau of Reference (Ure et al. 1993): obtém-se a concentração dos metais ligados às fraçôes geoquímicas do sedimento. A primeira etapa da extração determina os metais solúveis em água e ácido fraco, os metais trocáveis e fracamente retidos na superfície dos sedimentos (fração F1); segunda etapa determina os metais ligados aos óxidos de ferro e manganês, instáveis em condiçôes redutoras por mudanças no potencial redox do sedimento (fração F2); a terceira etapa ocorre a degradação da matéria orgânica sob condiçôes oxidantes, com o desprendimento dos metais ligados a sulfetos e complexados na matéria orgânica (fração F3); a quarta e última etapa do procedimento BCR é a digestão total do resíduo das etapas anteriores (fração $\mathrm{F} 4$ ). $\mathrm{O}$ protocolo de extração descrito na Tabela 2 foi aplicado somente às amostras dos pontos P2 e $\mathrm{P} 8$, por representarem interferências antrópicas no Rio Bento Gomes (P2: área em frente a uma fazenda de gado; P8: área à jusante da ponte próxima à captação da água da cidade).

As concentraçóes dos metais nos extratos sobrenadantes obtidos foram determinadas em Espectrômetro de Emissão Atômica com Fonte de Plasma Indutivamente Acoplado (Thermo Scientific, ICP-OES ICAP 6000 Series, Cambridge, Inglaterra), no Laboratório de Controle Analítico de Combustível (CEANC), da Universidade Federal de Mato Grosso.

Para fins de validação da acurácia do método, foi analisado o material de referência certificado BCR701 (Community Bureau Reference $\mathrm{n}^{\circ}$ 0318), com concentraçóes certificadas para metais, pelos protocolos acima descritos, calculando-se os porcentuais de recuperação (\%R).

\section{Grau de poluição ambiental e Fator de mobilidade dos metais}

Para avaliação do grau de poluição ambiental dos sedimentos foram adotados os níveis de referência para metais obtidos na Resolução CONAMA no 454 (Conama 2012) e os valores citados pela Agência de Proteçáo Ambiental Americana - EPA (Thomas 1987) para metais em sedimentos. A Resoluçáo 
Tabela 2. Protocolo analítico da extração sequencial pelo método BCR, do European Community Bureau of Reference (Ure et al. 1993).

\begin{tabular}{|c|c|c|c|c|}
\hline Fração & $\begin{array}{l}\text { Fase extraível do metal no } \\
\text { sedimento }\end{array}$ & Reagentes / Concentração & $\begin{array}{l}\text { Temperatura de } \\
\text { extração }\left({ }^{\circ} \mathrm{C}\right)\end{array}$ & Condições operacionais \\
\hline $\begin{array}{l}\text { F1 } \\
\text { (trocável; biodisponível) }\end{array}$ & $\begin{array}{l}\text { Ligado a cátions trocáveis e } \\
\text { carbonatos }\end{array}$ & Ácido acético 0,11 $\mathrm{mol} \mathrm{L}^{-1}$ & $22 \pm 5$ & $\begin{array}{c}\text { Agitação mecânica em agitador } \\
\text { do tipo "end-over-end", por } 16 \\
\text { h ("overnight") }\end{array}$ \\
\hline $\begin{array}{l}\text { F2 } \\
\text { (redutível; biodisponível em } \\
\text { ambiente redutor) }\end{array}$ & $\begin{array}{l}\text { Ligado a óxidos e hidróxidos de } \\
\text { Fe e Mn }\end{array}$ & $\begin{array}{l}\text { Cloridrato de Hidroxilamina } 0,5 \\
\qquad \mathrm{~mol} \mathrm{~L}^{-1}(\mathrm{pH} \mathrm{2})\end{array}$ & $22 \pm 5$ & $\begin{array}{c}\text { Agitação mecânica em agitador } \\
\text { do tipo "end-over-end", por } 16 \\
\text { h ("overnight") }\end{array}$ \\
\hline $\begin{array}{l}\text { F3 } \\
\text { (oxidável; relativamente } \\
\text { biodisponível) }\end{array}$ & $\begin{array}{l}\text { Complexado pela matéria } \\
\text { orgânica e sulfetos }\end{array}$ & $\mathrm{H}_{2} \mathrm{O}_{2} 8,8 \mathrm{~mol} \mathrm{~L}^{-1}$ & $\begin{array}{l}22 \pm 5 \\
85 \pm 2\end{array}$ & $\begin{array}{c}\text { Digestão por } 1 \mathrm{~h} \text { com agitação } \\
\text { ocasional } \\
\text { Digestão por } 1 \mathrm{~h}\end{array}$ \\
\hline $\begin{array}{l}\text { F4 } \\
\text { (residual; não biodisponível) }\end{array}$ & $\begin{array}{l}\text { Associado aos minerais } \\
\text { silicatados }\end{array}$ & 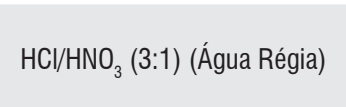 & $\begin{array}{l}22 \pm 5 \\
85 \pm 2\end{array}$ & $\begin{array}{l}\text { Repouso por } 16 \mathrm{~h} \\
\text { Aquecimento por } 2 \mathrm{~h}, \text { com } \\
\text { agitação ocasional. }\end{array}$ \\
\hline
\end{tabular}

CONAMA no 454 (Conama 2012) estabelece os níveis de classificação do material a ser dragado (sedimento) para os elementos $\mathrm{As}, \mathrm{Cd}, \mathrm{Pb}, \mathrm{Cu}, \mathrm{Cr}, \mathrm{Hg}$, Ni e $\mathrm{Zn}$, tendo como referência a legislação canadense (Canadian Sediment Quality Guidelines for the Protection of Aquatic Life) elaborada pelo CCME (Canadian Council of Ministers of the Environment) (Ccme 1999). Essa legislação normatiza os valores-guias de qualidade dos sedimentos, representados por dois valores: TEL (threshold effect level) e PEL (probable effect level), respectivamente Nível-1 e Nível- 2 da Resolução CONAMA no 454 (Nível 1: limiar abaixo do qual há menor probabilidade de efeitos adversos à biota; Nível 2: limiar acima do qual há maior probabilidade de efeitos adversos à biota).

A mobilidade dos metais no meio aquático foi avaliada pelo Fator de Mobilidade (FM) proposto por Sahuquillo et al. (2003), cujo cálculo consiste na divisão das concentrações dos metais da primeira fração extraível (F1) pela somatória das demais frações $\left(\sum[\mathrm{F} 1+\mathrm{F} 2+\mathrm{F} 3+\mathrm{F} 4]\right)$, obtidas na extração sequencial, sendo expresso em percentagem conforme a equação (1):

$$
\text { (1) } \mathrm{FM}=\left[\frac{\mathrm{F} 1}{\sum(\mathrm{F} 1+\mathrm{F} 2+\mathrm{F} 3+\mathrm{F} 4)}\right] \mathrm{X} 100
$$

\section{Análise estatística}

Os resultados foram tratados estatisticamente utilizandose a Análise de Agrupamento Hierárquico (HCA) para a identificação dos grupos de elementos com comportamento similar. Essa técnica foi utilizada para classificar as variáveis (metais) e as amostras de sedimentos de acordo com a similaridade da composição química (concentração dos metais). O resultado dessa análise foi expresso na forma de dendogramas, que são gráficos bidimensionais de fácil visualização. Os resultados da extração pseudo-total dos metais e os parâmetros físico-químicos do sedimento do Rio Bento Gomes também foram submetidos à Análise multivariada de Componentes Principais (PCA), a fim de demostrar as principais correlaçôes entre as variáveis e o seu agrupamento, sendo complementar à HCA. O tratamento estatístico dos resultados foi realizado por meio do software Action (Estatcamp 2014) integrado à planilha Excel (Microsoft).

\section{RESULTADOS}

Geralmente, os sedimentos amostrados consistem basicamente de areia e pouca fraçáo fina (silte e argila), exceto nos pontos P6 e P7, cuja granulometria foi alterada no período chuvoso, com maiores teores da fraçáo fina (Tabela 3). O pH das amostras de sedimento variou de 5,1 a 6,2 no período seco e de 4,5 a 5,3 no período chuvoso. $\mathrm{O}$ teor de carbono orgânico total variou de $0,76 \%$ a $2,25 \%$ no período seco e de 0,43 a 3,32\% no período chuvoso, com médias de $1,66 \%$ e 1,94\%, respectivamente.

De acordo com as concentraçóes pseudo-totais (Tabela 4), os metais com maior ocorrência nas amostras foram o ferro e o manganês, com médias de $7,54 \mathrm{~g} \mathrm{~kg}^{-1}$ e $340,35 \mathrm{mg} \mathrm{kg}$, respectivamente, no período seco e de 7,69 $\mathrm{g} \mathrm{kg}^{-1}$ e 289,94 mg $\mathrm{kg}^{-1}$, no período chuvoso. A ordem de predominância dos metais nos sedimentos variou sazonalmente, sendo $\mathrm{Fe}>\mathrm{Mn}>\mathrm{Zn}>\mathrm{Cr}$ $>\mathrm{Cu}>\mathrm{Ni}$ no período seco e $\mathrm{Fe}>\mathrm{Mn}>\mathrm{Zn}>\mathrm{Cu}>\mathrm{Cr}>\mathrm{Ni}$ no período chuvoso.

O fator de mobilidade individual (Fmi) médio dos metais (Figura 2) revela que os metais mais móveis foram o Mn seguido do $\mathrm{Zn}$ (no período seco) e do $\mathrm{Ni}$ (no período chuvoso), com Fmi variando de 55,1 a 96,8 (Mn), 22,8 a 63,2 ( $\mathrm{Zn})$ e 18,3 a 37,5 $(\mathrm{Ni})$, enquanto que o metal menos móvel foi o Fe $(3,4$ a 10,5$)$. A maioria dos metais apresentaram maior Fmi na época chuvosa no Pantanal, com exceção do cobre.

A análise de agrupamento (HCA) para ambos os períodos (Figuras 3 e 4) associa os metais estudados com as características do sedimento, sendo uma ferramenta complementar à correlação de Pearson. Observa-se nos dendogramas dos metais (Figuras $3 \mathrm{~A} \mathrm{e}$ 3B) a associação dos metais entre si, em ambos períodos sazonais. 
Tabela 3. Resultados analíticos de caracterização do sedimento do Rio Bento Gomes nos dois períodos amostrais.

\begin{tabular}{|c|c|c|c|c|c|c|c|c|c|c|}
\hline \multirow{3}{*}{ AMOSTRAS } & \multicolumn{5}{|c|}{ Período seco } & \multicolumn{5}{|c|}{ Período chuvoso } \\
\hline & Areia & Silte & Argila & \multirow{2}{*}{$\mathrm{pH}$} & \multirow{2}{*}{$\begin{array}{c}\mathrm{COT}^{1} \\
(\%)\end{array}$} & Areia & Silte & Argila & \multirow{2}{*}{$\mathrm{pH}$} & \multirow{2}{*}{$\begin{array}{c}\mathrm{COT}^{1} \\
(\%)\end{array}$} \\
\hline & \multicolumn{3}{|c|}{$\left(\mathrm{g} \mathrm{kg}^{-1}\right)$} & & & \multicolumn{3}{|c|}{$\left(\mathrm{g} \mathrm{kg}^{-1}\right)$} & & \\
\hline P1 & 727 & 67 & 206 & 5,1 & 2,13 & 851 & 34 & 115 & 5,3 & 3,21 \\
\hline P2 & 794 & 49 & 157 & 6,2 & 1,55 & 634 & 67 & 299 & 4,95 & 2,52 \\
\hline P3 & 827 & 33 & 157 & 5,9 & 2,05 & 701 & 50 & 249 & 4,93 & 1,54 \\
\hline P4 & 794 & 49 & 206 & 6,2 & 0,76 & 784 & 33 & 183 & 4,82 & 1,38 \\
\hline P5 & 727 & 67 & 206 & 6,2 & 1,92 & 734 & 50 & 216 & 4,63 & 1,49 \\
\hline P6 & 727 & 67 & 157 & 5,8 & 1,84 & 184 & 183 & 633 & 4,76 & 2,39 \\
\hline P7 & 794 & 49 & 240 & 5,9 & 2,25 & 484 & 133 & 383 & 4,55 & 2,53 \\
\hline P8 & 794 & 66 & 206 & 6,0 & 0,83 & 801 & 50 & 149 & 4,93 & 0,43 \\
\hline
\end{tabular}

${ }^{1}$ COT: carbono orgânico total.

Tabela 4. Concentrações pseudo-totais dos metais no sedimento do Rio Bento Gomes nos dois períodos amostrados.

\begin{tabular}{|c|c|c|c|c|c|c|}
\hline \multirow{2}{*}{ Amostras } & $\mathrm{Cr}$ & $\mathrm{Ni}$ & $\mathrm{Cu}$ & $\mathrm{Mn}$ & $\mathrm{Zn}$ & $\mathrm{Fe}$ \\
\hline & \multicolumn{5}{|c|}{$\mathrm{mg} \mathrm{kg}^{-1}$} & $\mathrm{~g} \mathrm{~kg}^{-1}$ \\
\hline \multicolumn{7}{|c|}{ Período seco } \\
\hline P1 & 21,85 & 12,36 & 13,70 & 227,50 & 20,41 & 13,94 \\
\hline P2 & 6,88 & 1,40 & 6,50 & 652,50 & 6,19 & 10,25 \\
\hline P3 & 5,38 & $<$ L.D & 0,48 & 385,33 & 8,43 & 6,11 \\
\hline P4 & 2,39 & $<$ L.D & 0,48 & 160,83 & 4,97 & 2,78 \\
\hline P5 & 5,38 & $<$ L.D & 1,68 & 394,16 & 6,47 & 5,97 \\
\hline P6 & 6,88 & $<$ L.D & 2,88 & 285,83 & 13,86 & 6,76 \\
\hline P7 & 3,38 & 4,12 & 6,49 & 327,50 & 17,42 & 8,79 \\
\hline P8 & 5,40 & $<\mathrm{LD}$ & 5,30 & 289,16 & 4,51 & 5,68 \\
\hline Média & 7,19 & 2,24 & 4,69 & 340,35 & 10,28 & 7,54 \\
\hline \multicolumn{7}{|c|}{ Período chuvoso } \\
\hline P1 & 8,38 & 15,11 & 16,10 & 285,33 & 20,32 & 5,10 \\
\hline P2 & 20,36 & 17,85 & 14,90 & 344,16 & 29,49 & 11,26 \\
\hline P3 & 15,36 & 15,11 & 18,50 & 302,50 & 36,97 & 15,53 \\
\hline P4 & 6,88 & 4,12 & 12,50 & 252,50 & 26,12 & 1,11 \\
\hline P5 & 5,38 & 2,75 & 6,49 & 152,50 & 15,64 & 4,01 \\
\hline P6 & 21,85 & 2,75 & 22,11 & 402,50 & 46,05 & 8,51 \\
\hline P7 & 8,40 & 26,09 & 22,11 & 444,16 & 38,56 & 15,17 \\
\hline P8 & 2,40 & 1,40 & 0,50 & 135,83 & 8,34 & 0,83 \\
\hline Média & 11,13 & 10,65 & 14,15 & 289,94 & 27,69 & 7,69 \\
\hline $\begin{array}{l}\text { Valor de referência } \\
\text { (Nível } 1 \text { - Nível 2) } \\
\text { (CONAMA 2012) }\end{array}$ & 37,3 - 90 & $18-35,9$ & $35,7-197$ & - & $123-315$ & - \\
\hline
\end{tabular}

LD: Limite de Detecção 


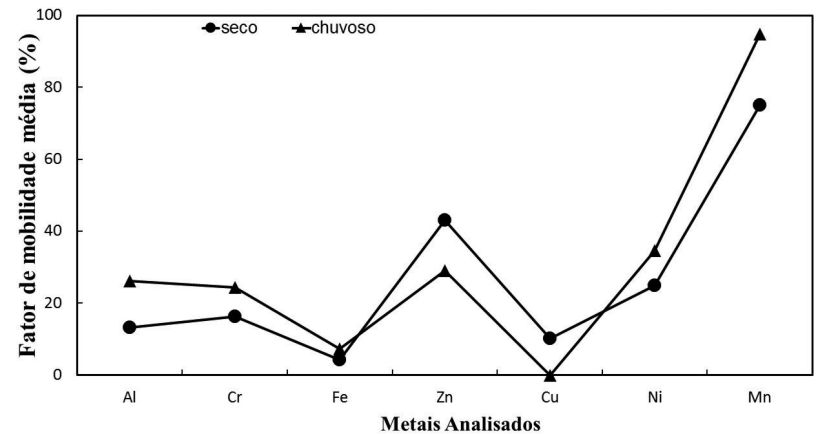

Figura 2. Comparação da mobilidade média dos metais estudados nas amostras de sedimento do Rio Bento Gomes.
Já as figuras 4A e 4B apresentam dendogramas construídos com as variáveis químicas e as concentraçôes dos metais nas amostras de sedimento coletadas nos dois períodos, para os oito pontos. Os resultados obtidos pela Análise de Componentes Principais (PCA) (Figura 5) são semelhantes aos obtidos pela HCA, pois também mostraram que é possível agrupar as amostras em classes distintas, separando os oito pontos de amostragem em três grupos principais: Grupo I - sedimentos com maiores teores de argila e silte (fração fina) e Zn, Mn; Grupo II - sedimentos com maiores teores de metais e carbono orgânico total; Grupo III - sedimentos arenosos e com pH mais elevado. O modelo explicou 90,46\% da variação dos dados na época chuvosa e $82,54 \%$ na época seca, considerando os três primeiros componentes principais.

A

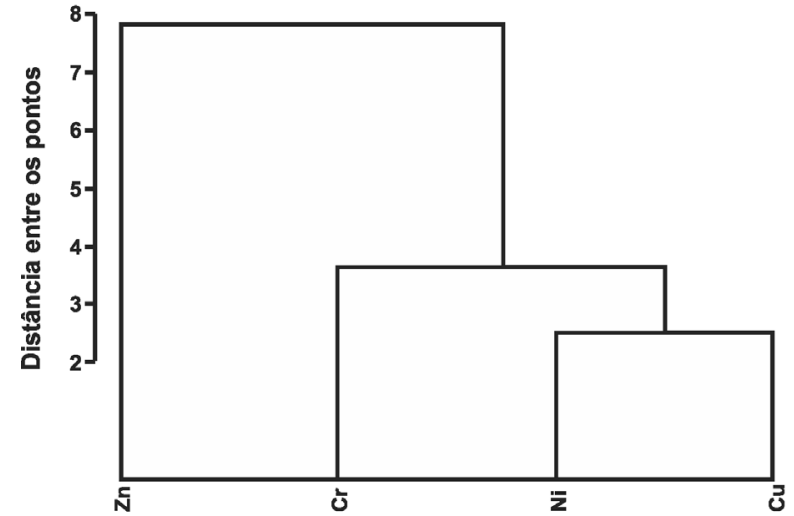

Agrupamento dos metais

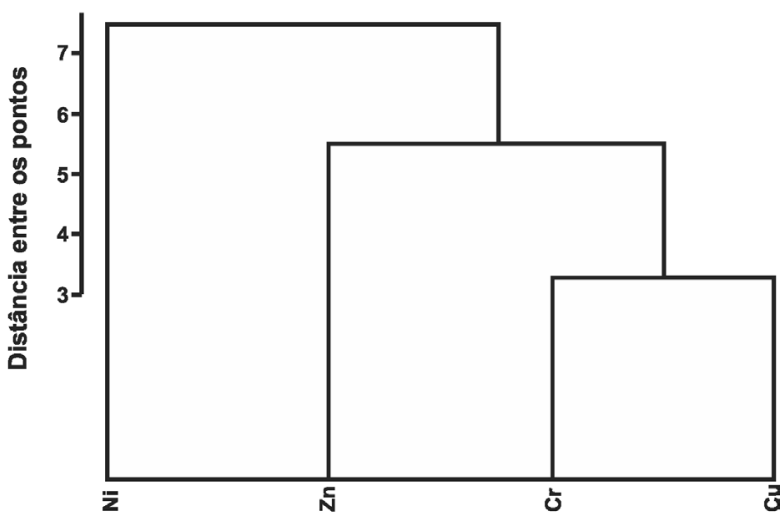

Agrupamento dos metais

Figura 3. Dendrograma da concentração dos elementos traço no sedimento (A) período chuvoso (A) período seco.
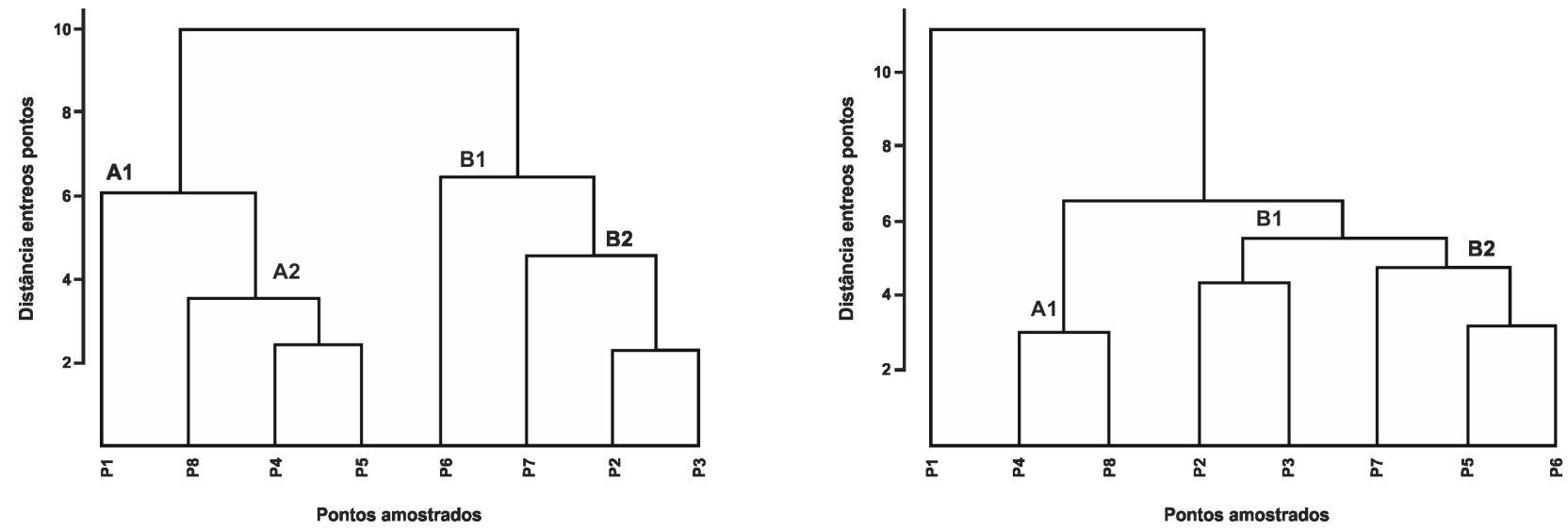

Figura 4. Dendrograma dos pontos de amostragem (A) período chuvoso (b) período seco. 
As concentrações dos metais nas fraçóes geoquímicas do sedimento obtidas pela extração sequencial, indicam que os sedimentos do Rio Bento Gomes concentram os metais na sequência: $\mathrm{Fe}>\mathrm{Mn}>\mathrm{Zn}>\mathrm{Ni}>\mathrm{Cr}>\mathrm{Cu}$ (período chuvoso) e $\mathrm{Fe}>\mathrm{Mn}>\mathrm{Zn}>\mathrm{Cu}>\mathrm{Cr}>\mathrm{Ni}$ (período seco), considerando o somatório das frações (Tabela 5). Observando a distribuição dos metais nas fraçóes (Figura 6), a maioria dos metais (com exceçấo do Cobre) encontram-se presentes em concentraçóes significativas em fraçôes potencialmente mobilizáveis no meio aquático $(\mathrm{F} 1+\mathrm{F} 2+\mathrm{F} 3)$.

O material de referência BCR-701 foi utilizado para garantir a qualidade do procedimento de extraçáo sequencial, e brancos analíticos foram avaliados em todas as fases da extração. As taxas de recuperação foram superiores a $86 \%$, com exceção do Cr que apresentou 70,4\% na fração 4 (residual). O $\mathrm{Ni}$ apresentou as maiores taxas de recuperaçáo para o material de referência utilizado, variando de $86,4 \%$ a $106 \%$.

A

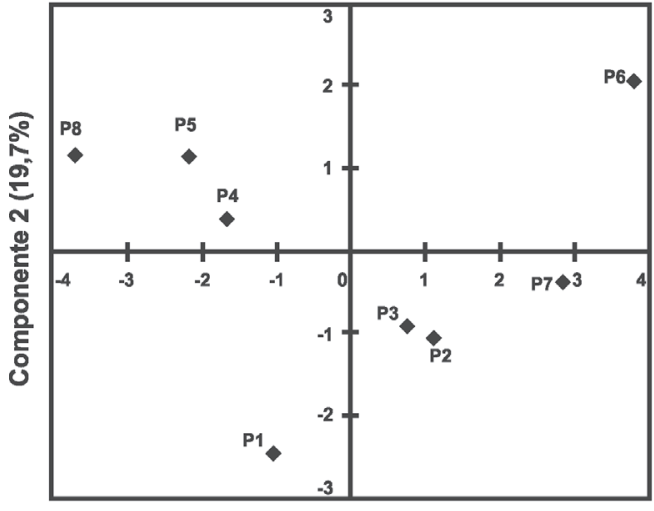

Componente $1(61,25 \%)$

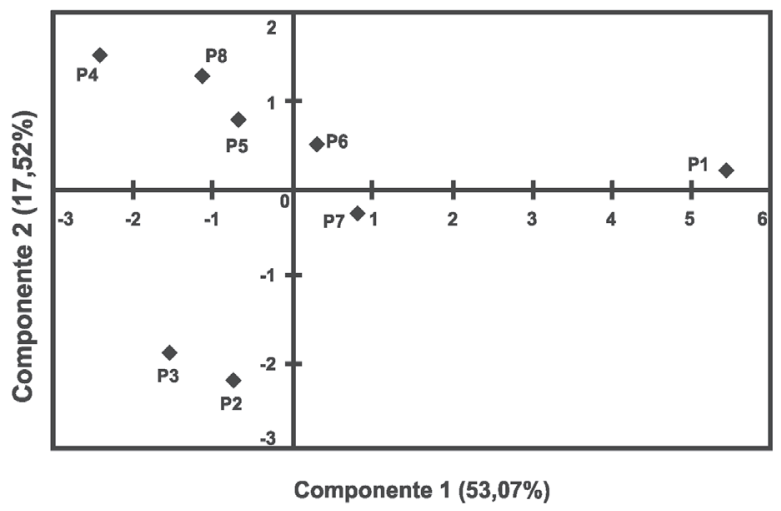

Figura 5. Componente principal (A) período chuvoso (B) período seco.
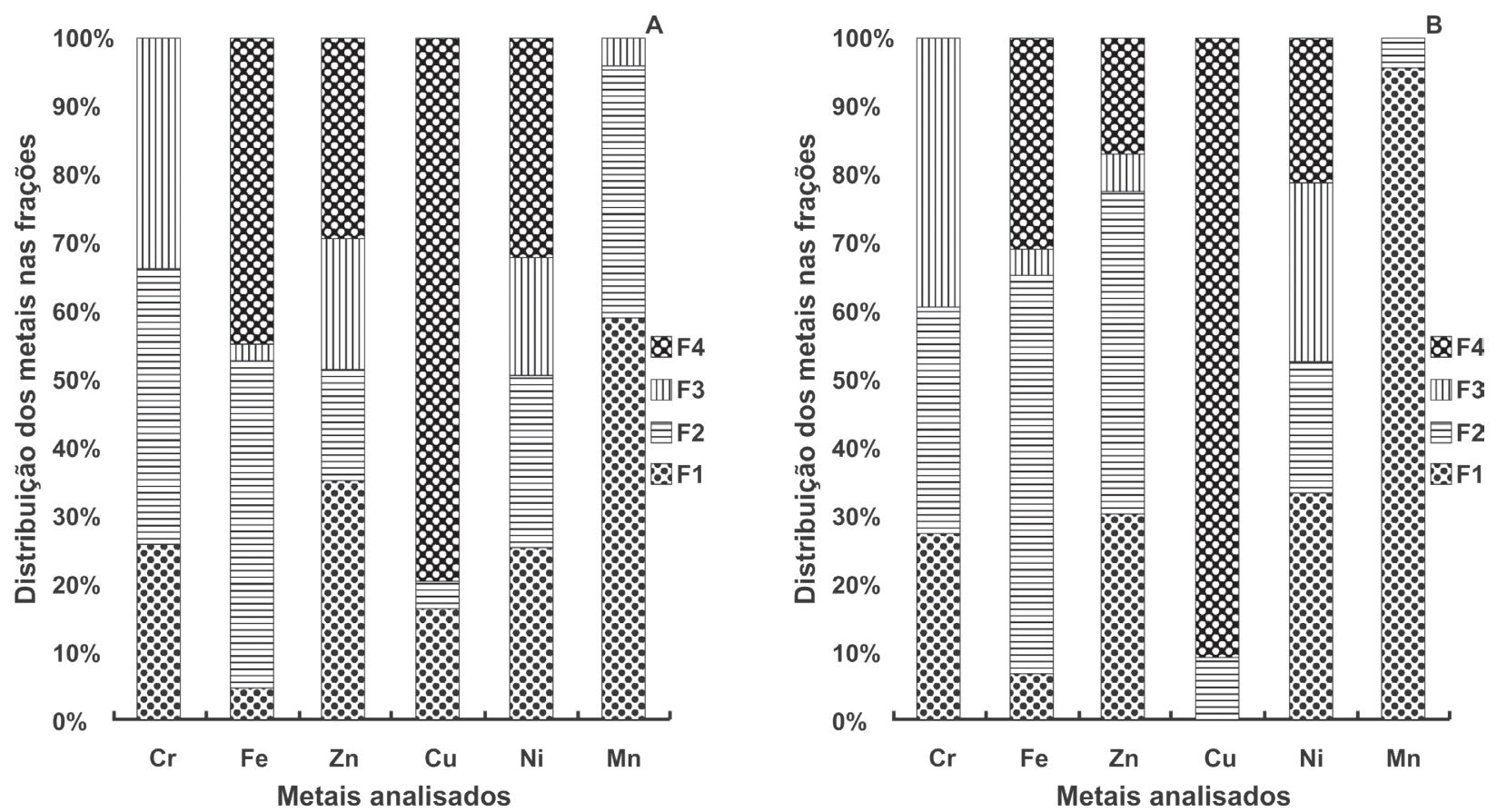

Figura 6. Distribuição porcentual dos metais nas frações extraíveis do sedimento (A) período chuvoso (B) período seco (F1: Fração trocável; F2: fração redutível; F3: fração oxidável; F4: fração residual). 
Tabela 5. Concentrações dos metais nas frações geoquímicas, pelo método de extração sequencial das amostras de sedimento do Rio Bento Gomes.

\begin{tabular}{|c|c|c|c|c|c|c|c|}
\hline \multirow{2}{*}{ Amostras } & \multirow{2}{*}{ Frações } & $\mathrm{Cr}$ & $\mathrm{Fe}$ & $\mathrm{Zn}$ & $\mathrm{Cu}$ & $\mathrm{Ni}$ & $\mathrm{Mn}$ \\
\hline & & \multicolumn{6}{|c|}{$\mathrm{mg} \mathrm{kg}^{-1}$} \\
\hline & \multicolumn{7}{|c|}{ Período seco } \\
\hline \multirow{5}{*}{$\mathrm{P} 2$} & $\mathrm{~F} 1$ & 1,8 & 4 & 7,8 & 3,3 & 1,7 & 356,8 \\
\hline & F2 & 5,6 & 4 & 6,0 & 0,8 & 1,7 & 261,8 \\
\hline & F3 & 4,2 & 2 & 8,5 & <L.D. & 1,7 & 29,1 \\
\hline & F4 & <L.D. & 3,10 & 10,5 & 12,0 & 4,2 & $<$ L.D. \\
\hline & Soma (F1 a F4) & 11,6 & 7,9 & 32,8 & 16,1 & 9,3 & 647,7 \\
\hline \multirow{6}{*}{ P8 } & $\mathrm{F} 1$ & 1,8 & 12 & 8,5 & $<$ L.D. & 3,3 & 69,1 \\
\hline & F2 & 2,8 & 1,3 & 1,6 & <L.D. & 3,3 & 3,6 \\
\hline & F3 & 2,8 & 5 & 0,5 & $<$ L.D. & 1,7 & $<$ L.D. \\
\hline & F4 & <L.D. & 2 & 2,9 & 4,0 & 2,1 & $<$ L.D. \\
\hline & Soma (F1 a F4) & 7,4 & 3,5 & 13,5 & 4,0 & 10,4 & 72,7 \\
\hline & \multicolumn{7}{|c|}{ Período chuvoso } \\
\hline \multirow{5}{*}{$\mathrm{P} 2$} & $\mathrm{~F} 1$ & 2,8 & 1 & 8,3 & $<$ L.D. & 3,3 & 109,1 \\
\hline & F2 & 2,8 & 1 & 13,6 & $<$ L.D. & 1,7 & 3,6 \\
\hline & F3 & 4,2 & 1 & 1,6 & $<$ L.D. & 3,3 & $<$ L.D. \\
\hline & F4 & <L.D. & 1 & 4,2 & 4,0 & 2,1 & $<$ L.D. \\
\hline & Soma (F1 a F4) & 9,8 & 2 & 27,7 & 4,0 & 10,4 & 112,7 \\
\hline \multirow{5}{*}{ P8 } & $\mathrm{F} 1$ & 1,8 & 1 & 2,7 & $<$ L.D. & 3,3 & 145,5 \\
\hline & F2 & 2,8 & 1,3 & 3,6 & 0,8 & 1,7 & 10,9 \\
\hline & F3 & 2,8 & 0 & 0,5 & <L.D. & 1,7 & $<$ L.D. \\
\hline & F4 & <L.D. & 26 & 2,9 & 2,8 & 2,1 & $<$ L.D. \\
\hline & Soma (F1 a F4) & 7,4 & 1,8 & 9,7 & 3,6 & 8,8 & 156,8 \\
\hline
\end{tabular}

$<$ L.D.: Inferior ao Limite de Detecção.

\section{DISCUSSÃO}

\section{Teor pseudo-total dos metais e as características físico-químicas do sedimento}

As maiores concentraçôes de carbono orgânico total nos sedimentos do Rio Bento Gomes ocorreram nas áreas de remanso (pontos P3, P6, P7) e, de acordo com Siqueira e Aprile (2013), maiores teores de carbono orgânico em ambientes de baixa energia e com predominância a sedimentos finos é normal, uma vez que esses são locais típicos de sedimentação. Isso pode ter contribuído para o aumento da concentração dos metais $\mathrm{Cu}$ e $\mathrm{Zn}$ nesses pontos. Santos et al. (2013) e Kalina et al. (2013) demonstraram que a matéria orgânica é muito importante na distribuição e dispersão dos metais, principalmente para o $\mathrm{Cu}$ e $\mathrm{Zn}$, que têm forte ligação com os compostos orgânicos no meio, uma vez que há formação de complexos estáveis e solúveis de íons metálicos com as substâncias húmicas, podendo servir como transportadores de metais tóxicos, incrementando o transporte no meio aquático (Meurer 2006).

Neste estudo, todos os metais correlacionaram-se positiva e significativamente com o teor de carbono orgânico total no período chuvoso $(\mathrm{r}=0,48(\mathrm{Cr}) ; 0,62(\mathrm{Ni}) ; 0,74(\mathrm{Cu}) ; 0,71$ $(\mathrm{Mn}) ; 0,49$ (Zn) e 0,44 (Fe), p<0,05), e somente o Zn, Ni e Fe no período seco $(\mathrm{r}=0,72(\mathrm{Zn}) ; 0,45(\mathrm{Ni}) ; 0,59(\mathrm{Fe}), \mathrm{p}<0,05)$.

É bem conhecido que a granulometria e o teor de matéria orgânica são fatores importantes que afetam a distribuição de metais traço (Farkas et al. 2009; Bartoli et al. 2012). Sedimentos de granulometria mais fina tendem a apresentar teores de metais relativamente mais elevados, em parte devido à elevada superfície específica das partículas, que aumenta a adsorçâo superficial no mineral e na matéria orgânica (Rubio et al. 2000). Neste estudo, as fraçôes silte e argila também contribuíram para maiores teores dos metais no período chuvoso, onde o aporte de sedimentos mais finos foi maior. 
Assim, todos os metais apresentaram coeficientes de correlaçáo de Pearson positivos e significativos com essas fraçóes.

As variaçōes de $\mathrm{pH}$ do sedimento foram pouco significativas, caracterizando acidez média a fraca, com menores valores no período chuvoso, provavelmente pela matéria orgânica carreada pela cheia no Pantanal. Todos os metais (exceto o $\mathrm{Mn}$ ) apresentaram correlação negativa e significativa com o $\mathrm{pH}$ do sedimento, no período seco $(\mathrm{r}=-0,89(\mathrm{Cr}) ;-0,88(\mathrm{Ni})$; $-0,76(\mathrm{Cu}) ;-0,83(\mathrm{Zn}) ;-0,73(\mathrm{Fe}), \mathrm{p}<0,05)$. Segundo Alloway (1990), o pH afeta a disponibilidade dos metais em solos e sedimentos por aumentar sua mobilidade em condiçôes ácidas.

Os metais tiveram forte correlação com o teor de $\mathrm{Fe}$ no período seco $(\mathrm{r}=0,82(\mathrm{Cr}) ; 0,85(\mathrm{Ni}) ; 0,91(\mathrm{Cu}) ; 0,72$ $(\mathrm{Zn}), \mathrm{p}<0,05)$ e chuvoso $(\mathrm{r}=0,58(\mathrm{Cr}) ; 0,78(\mathrm{Ni}) ; 0,74$ $(\mathrm{Cu}) ; 0,73(\mathrm{Zn}) ; 0,75(\mathrm{Mn}), \mathrm{p}<0,05)$, sugerindo adsorção na forma de precipitado de óxidos/hidróxidos de Ferro. A precipitação de óxidos hidratados de Fe está associada com o transporte e a disponibilidade de metais traço, que influenciam as trocas na interface água-sedimento. Verificase que as concentrações maiores de Fe são nos pontos $\mathrm{P} 1$ e P2 no período seco e P7 no período chuvoso, para os quais correspondem também às maiores concentraçôes dos demais elementos.

Ao comparar os resultados obtidos dos teores pseudototais (Tabela 4) com os valores de referência para metais estabelecidos pela legislação ambiental brasileira e canadense, observa-se que todos os metais apresentaram teores dentro dos limites, no período seco. Entretanto, o $\mathrm{Ni}$ apresentou teores acima do nível 1 permitido no período chuvoso no ponto P7, uma área de remanso do rio, onde os teores de matéria orgânica são maiores, especialmente durante a cheia no Pantanal.

De acordo com os limites previstos pela EPA (Thomas 1987), a concentraçấo de Ni no ponto P7 (chuvoso) classificaria o sedimento como moderadamente poluído (20 - $50 \mathrm{mg} \mathrm{kg}^{-1}$ ). Quanto aos teores de Mn, a EPA considera o sedimento como: não poluído com teor inferior a $300 \mathrm{mg} \mathrm{kg}^{-1}$, moderadamente poluído entre $300 \mathrm{e} 500 \mathrm{mg} \mathrm{kg}^{-1} \mathrm{e}$ altamente poluído com teores acima de $500 \mathrm{mg} \mathrm{kg}^{-1}$. Tomando por base esse critério, os teores de Mn classificam o sedimento do Rio Bento Gomes como poluído no ponto P2 (época seca), enquanto que nos demais pontos, o sedimento é considerado moderadamente poluído (nos pontos P3, P5, P6, P7).

Comparando os resultados deste trabalho com outros similares em sistemas aquáticos superficiais, nota-se que as concentraçôes de $\mathrm{Ni}, \mathrm{Zn}$ e $\mathrm{Cu}$ encontradas neste estudo foram mais elevadas que as obtidas por Baggio e Horn (2008) no Rio Formoso/MG e por Saraiva et al. (2009) no Ribeirão Espirito Santo/MG, ambos corpos hídricos com fontes pontuais e difusas de poluição por atividades industriais e agropecuárias.

\section{Análise estatística multivariada}

A análise multivariada é um método estatístico utilizado para explicar variabilidade entre variáveis observadas, e foi aplicada para elucidar os padróes relevantes de contaminação pelos metais no sedimento. Pela análise de agrupamento hierárquico (HCA), os dendogramas (Figura 3) demonstram que os metais $\mathrm{Cr}$, $\mathrm{Cu}$ e Ni estão associados devido à forte adsorção aos óxidos de ferro nas fraçóes mais finas do sedimento, além de sua mobilidade no meio aquático serem semelhantes. Destacam-se dois grandes grupos no período chuvoso (Figura 4A): um composto pelas amostras com altos teores de ferro e matéria orgânica (pontos P7, P2 e P3); e outro grupo que apresenta baixos valores de $\mathrm{pH}$, matéria orgânica e teor de ferro no sedimento (pontos P4 e P5), fatores que afetam a mobilidade dos metais no meio aquático.

No período seco (Figura 4B) se observam os grupos: pontos P4 e P8 agrupados em função dos baixos valores de matéria orgânica e metais extraíveis; pontos $\mathrm{P} 5$ e P6, e em menor grau o ponto $\mathrm{P} 7$, cujos sedimentos apresentam maiores teores de argila e matéria orgânica; e o grupo formado pelos pontos $\mathrm{P} 2$ e $\mathrm{P} 3$, com maiores teores de areia e cromo. O ponto P1 se distanciou dos demais, por constituir o leito de sedimento seco, onde a condição de $\mathrm{pH}$ é diferenciada e influi na disponibilidade dos metais no meio.

De acordo com os resultados da Análise de Componentes Principais (Figura 5), observa-se que há distinção entre os grupos principais, a julgar pelos escores das componentes principais e suas correlaçóes com as variáveis analisadas. $\mathrm{Na}$ época seca (Figura 5A), os pontos P2 e P3 agrupam-se pela associação dos seus teores de areia, $\mathrm{pH}$ e $\mathrm{Mn}$; os pontos $\mathrm{P}$ 5, P6 e P7 e, em menor grau o ponto P4, formam um grupo relacionado pelos teores da fração fina (silte, argila), carbono total e os teores de $\mathrm{Cr}, \mathrm{Ni}, \mathrm{Cu}, \mathrm{Zn}$ e Fe; no ponto P1 se distanciou dos demais por ser um leito de sedimento seco, portanto com valores das variáveis diferenciados dos demais pontos. Na época chuvosa (Figura 5b), os pontos P2 e P3 e em menor grau, o ponto P7 agruparam-se em função dos teores de carbono orgânico, $\mathrm{Cr}, \mathrm{Ni}, \mathrm{Cu}, \mathrm{Mn}$ e Fe; os pontos $\mathrm{P} 6$ e $\mathrm{P} 1$ constituíram dois extremos, provavelmente em função das diferenças na textura e $\mathrm{pH}$ do sedimento; e os demais pontos $\mathrm{P} 5, \mathrm{P} 4$ e em menor grau $\mathrm{P} 8$ agruparam-se em função da textura mais fina do sedimento e do teor de $\mathrm{Zn}$.

\section{Fracionamento geoquímico dos metais}

Dentre os pontos amostrais avaliados, o ponto P2 concentra a maioria dos metais, provavelmente em função das atividades agropecuárias desenvolvidas na região, contribuindo como fonte difusa de poluição por metais no sedimento, por escoamento superficial do solo. As partículas transportadas e depositadas nas margens podem conter resíduos de agroquímicos adsorvidos nos coloides, e metais como sais 
de $\mathrm{Zn}, \mathrm{Cu}$ e $\mathrm{Pb}$ e compostos metalo-orgânicos normalmente fazem parte de princípios ativos de vários agroquímicos (Owens 2005; Rosolen et al. 2009).

Analisando a distribuição porcentual média dos metais nas fraçôes (com base na contribuição de cada fração na concentraçáo total) (Figura 6), verifica-se que na fração F1 (trocável) a sequência é: $\mathrm{Mn}(59 \%)>\mathrm{Zn}(35 \%)>\mathrm{Cr}(26 \%)$ $>\mathrm{Ni}(25 \%)>\mathrm{Cu}(16 \%)>\mathrm{Fe}(5 \%)$, no período seco; $\mathrm{Mn}$ $(95 \%)>\mathrm{Ni}(34 \%)>\mathrm{Zn}(30 \%)>\mathrm{Cr}(27 \%)>\mathrm{Fe}(7 \%)$ no período chuvoso. Essa é a fração de maior interesse ambiental por caracterizar as formas mais móveis dos metais no meio, e consequentemente, com maior potencial de lixiviaçáa (Jalali e Hemati 2013). Nota-se que o Mn é o elemento móvel no sedimento analisado, nos dois períodos, provavelmente em função da sua maior solubilidade em meio redutor. Em geral, a elevada proporção de metais pesados nas fraçôes biodisponíveis pode sugerir uma maior contribuiçáo de fontes antropogênicas (Wang et al. 2002).

$\mathrm{Na}$ fração F2 (redutível), os metais se distribuíram diferentemente nos dois períodos de amostragem: $\mathrm{Fe}(48 \%)$ $>\mathrm{Cr}(40 \%)>\mathrm{Mn}(37 \%)>\mathrm{Ni}(25 \%)>\mathrm{Zn}(16 \%)>\mathrm{Cu}(4 \%)$ na época seca; $\mathrm{Fe}(57 \%)>\mathrm{Zn}(46 \%)>\mathrm{Cr}(33 \%)>\mathrm{Ni}(18 \%)$ $>\mathrm{Cu}(11 \%)>\mathrm{Mn}(5 \%)$ na época chuvosa.

Isso demonstra que o sedimento do Rio Bento Gomes acumula principalmente os metais $\mathrm{Cr}$ e $\mathrm{Zn}$ nos óxidos e hidróxidos de $\mathrm{Fe}$ e de $\mathrm{Mn}$. Óxidos e hidróxidos juntamente com matéria orgânica são reconhecidos como adsorventes de metais em sistemas aquáticos (Shikazono et al. 2012). Os óxidos de ferro hidratados mais comuns são a ferrihidrita, hematita e goethita, e exibem diferentes potenciais de adsorção de metais (Alloway 1990). Porém, os metais adsorvidos aos óxidos de ferro e manganês se tornam disponíveis em ambientes altamente redutores (Peng et al. 2009). No período chuvoso, a carga orgânica nos rios do Pantanal aumenta a ponto de diminuir o oxigênio dissolvido na água, e condiçóes anóxicas podem ocorrer em determinadas áreas de remanso do rio. Em tais ambientes esses metais seriam facilmente liberados para o meio aquático.

A fração F3 (oxidável) concentra os metais associados à matéria orgânica. Nos sedimentos do Rio Bento Gomes, a porcentagem de ocorrência os metais é: $\operatorname{Cr}(34 \%)>\operatorname{Zn}(19 \%)$ $>\mathrm{Ni}(17 \%)>\mathrm{Mn}(4 \%)>\mathrm{Fe}(2,4 \%)>\mathrm{Cu}(0 \%)$ (época seca); $\mathrm{Cr}(41 \%)>\mathrm{Ni}(26 \%)>\mathrm{Zn}(5,5 \%)>\mathrm{Fe}(4 \%)>\mathrm{Mn}=\mathrm{Cu}$ (0\%) (época chuvosa). Cabe destacar a importância da matéria orgânica, amplamente presente neste ambiente, na formação de complexos de cromo, que podem estar em solução ou ainda mais provavelmente em suspensão, compondo o valor de cromo total na água. Porém, uma vez que os sedimentos sáo secos, a oxidação da matéria orgânica torna-se mais rápida e o risco de liberação desses metais no ambiente é maior (Reddy e Delaune 2008). Dessa forma, alteraçôes nas propriedades físico-químicas do sedimento ( $\mathrm{pH}, \mathrm{Eh})$ podem resultar em mudanças no equilíbrio do $\mathrm{Cr}$ (III) - Cr(VI), formas de cromo que são consideradas de importância biológica.

Os metais extraídos nas frações residuais (F4) estão fixados no reticulo cristalino dos silicatos minerais estáveis e resistentes ao intemperismo, e estão indisponíveis no meio (Bevilacqua et al. 2009). Neste estudo, os metais que estiveram associados a essa fração são: $\mathrm{Cu}(80-90 \%), \mathrm{Fe}(32-45 \%), \mathrm{Ni}(22-$ $32 \%)$ e $\mathrm{Zn}(19$ - 29\%). Embora a fração residual não tenha importância ambiental direta por se tratar de contribuiçôes litogênicas do metal no meio, baixos valores verificados para esta fração podem indicar influência de fontes poluidoras alóctones que se acumulam nos sedimentos de fundo.

\section{CONCLUSÕES}

Os maiores teores dos metais no sedimento encontram-se nas fraçôes geoquímicas menos estáveis (na forma trocável, ligados a óxidos de ferro e à matéria orgânica), com exceção do cobre, cuja fração geoquímica de maior representatividade é a residual, ou seja, ligada aos minerais do sedimento. Os metais mais móveis no meio e, consequentemente, mais disponíveis, foram o manganês, zinco e níquel, principalmente na época chuvosa. Os métodos de análise multivariada foram úteis para demonstrar a diferenciação entre os pontos amostrados ao longo do rio, além de indicarem que a distribuiçâo geoquímica dos metais é influenciada pelas características físicas e químicas do sedimento e pela sazonalidade.

\section{AGRADECIMENTOS}

Ao Instituto Federal de Mato Grosso pelo apoio logístico, à Universidade Federal de Mato Grosso pela realização das análises dos metais e à Coordenação de Aperfeiçoamento de Pessoal do Ensino Superior (Capes) pela bolsa de estudos concedida.

\section{BIBLIOGRAFIA CITADA}

Ab' Saber, A. N. 1988. The Pantanal of Mato Grosso and the theory of refugia. Revista Brasileira de Geografia, 50:9-57.

Alloway, B.J. 1990. Heavy metals in soils. John Wiley \& Sons, New York, 339p.

Baggio, H.; Horn, H. A.2008. Contribuições naturais e antropogênicas para a concentração e distribuição de metais pesados em sedimento de corrente no Rio do Formoso, município de Buritizeiro - MG. Geonomos, 16:91-98.

Bartoli, G.; Papa, S.; Sagnella, E.; Fioretto, A. 2012. Heavy metal content in sediments along the Calore river: Relationships with physicalechemical characteristics. Journal of Environmental Management, 95: S9-S14.

Bevilacqua, J.E.; Silva, I.S.; Lichtig, J.; Masini, J.C. 2009. Extração seletiva de metais pesados em sedimentos de fundo do Rio Tietê, São Paulo. Química Nova, 32:26-33. 
Brasil.1982. Ministério das Minas e Energia. Folha SD-21 - Cuiabá. Levantamento de recursos naturais. Secretaria Geral, Projeto RADAM-BRASIL. RJ, 544 p.

Ccme.1999. Canadian Council of Ministers of the Environment. Canadian environmental quality guidelines for the protection of aquatic life. (http://www.ccme.ca/assets/pdf/pn_1497_waste_ char.rpt_final_e.pdf). Acesso em 10/03/2015.

Conama. 2012. Conselho Nacional do Meio Ambiente. Resolução n. 454. (http://www.mma.gov.br/port/conama/legiabre. cfm?codlegi=693). Acesso em 14/03/2014.

Davutluoglu, O.I.; Galip, S.; Cagatayhan B. E.; Turan, Y.; Bulent, S. 2011. Heavy metal content and distribution in surface sediments of the Seyhan River, Turkey. Journal of Environmental Management, 92:2250-2259.

Devesa-Rey, R.; Díaz-Fierros, F.; Barral, M. T. 2010. Trace metals in river bed sediments: an assessment of their partitioning and bioavailability by using multivariate exploratory analysis. Journal of Environmental Management, 9:2471-2477.

Estatcamp. 2014.Estatcamp - Consultoria em estatística e qualidade. Software Action. São Carlos, SP. (http://www.portalaction.com. br). Acesso em 22/09/2014.

Farkas, A.; Erratico, C.; Vigano, L., 2009. Assessment of the environmental significance of heavy metal pollution in surficial sediments of the River Po. Chemosphere, 68:761-768.

Fernandes, I. M.; Signor, C. A.; Penha, J. 2010. Biodiversidade no Pantanal de Poconé. Centro de Pesquisa do Pantanal, Cuiabá, $196 \mathrm{p}$.

Förstner, U. 1995. Non-linear release of metals from aquatic sediments. In: Salomons, W.; Stigliani, W. M. (Ed.). Biogeodynamics of pollutants in soils and sediments. Springer, Berlim, p. 247-307.

Gleyzes, C.; Tellier, S.; Astruc, M. 2002. Fractionation studies of trace elements in contaminated soils and sediments: a review of sequential extraction procedures. Trends in Analytical Chemistry, 21:451-467.

Hortellani, M.A.; Sarkis, J.E.S.; Abessa, D.M.S.; Sousa, E.C.P.M. 2008. Avaliação da contaminação por elementos metálicos dos sedimentos do Estuário Santos - São Vicente. Química Nova, 31:10-19.

Jalali, M.; Hemati, N. 2013. Chemical fractionation of seven heavy metals (Cd, Cu, Fe, Mn, Ni, Pb, and $\mathrm{Zn}$ ) in selected paddy soils of Iran. Paddy and Water Environment, 11:299-309.

Kalina, M.; Klučáková, M.; Sedláček, P. 2013. Utilization of fractional extraction for characterization of the interactions between humic acids and metals. Geoderma, 207:92-98.

Karbassi, A.; Bidhendi, G.; Pejman, A.; Bidhendi, M. E. 2010. Environmental impacts of desalination on the ecology of Lake Urmia. Journal of Great Lakes Research, 36:419-424.

Loureiro, D.; Fernandez, M.; Herms, F.; Araújo, C.; Lacerda, L. D. 2012. Distribuição dos metais pesados em sedimentos da Lagoa Rodrigo de Freitas. Oecologia Australis, 16:353-364.

Machado, M. P.; Pires, L. R.; Silva, L. T. P.; Riguete, J. R.; Silva, A. G. 2012. Análise de um gradiente fitofisionômico em área de influência de inundação periódica no Pantanal de Poconé, Mato Grosso, Brasil. Natureza on line, 10:65-70.
Martins, C.A.S.; Nogueira, N. O.; Ribeiro, P.H.; Rigo, M.M.; Candido, M.O. 2013. A dinâmica de metais-traço no solo. Current Agricultural Science and Technology, 17:383-391.

Meurer, E.J. 2006. Potássio. In: Fernandes, M.S. (Ed). Nutrição mineral de plantas. Universidade Federal de Viçosa, Viçosa, Minas Gerais, p.281-298.

Oliveira, D.; Oliveira, R. C. B.; Marins, R. V. 2011. Dinâmica de metais traço em solo e ambiente sedimentar estuarino como um fator determinante no aporte desses contaminantes para o ambiente aquático: revisão. Revista Virtual Quimica, 3:88-102.

Owens, P.N. 2005. Conceptual models and budgets for sediment management at the River Basin Scale. Journal Soils and Sediments, 5:201-212.

Peng, J.F.; Song, Y.H.; Yuan, P.; Cui, X.Y.; Qiu, G.L. 2009. The remediation of heavy metals contaminated sediment. Journal of Hazardous Materials, 161:633-640.

Pereira Filho, S. R. 1995. Metais pesados nas sub-bacias hidrográficas de Poconé e Alta Floresta. Saulo Rodrigues Pereira Filho - Rio de Janeiro. CETEM/CNPq.

Pueyo, M.; Mateu, J.; Rigol, A.; Vidal, M.; Lopez-Sanchez; J.F.; Rauret G. 2008. Use of modified BCR three-step sequential extraction procedure for the study of trace elements dynamics in contaminated soils. Environmental Pollution, 152:330-341.

Reddy, K. R.; Delaune, R.D. 2008. Biogeochemistry of wetlands: Science and applications. CRC press. Boca Raton, 774p.

Rosolen, V.; Herpin, U.; Coelho, N. M. M.; Coelho, L. M.; Brito, J. L. S. B.; Silva, L. A.; Lima, S. C. 2009. Qualidade dos sedimentos no rio Uberabinha (Uberlândia, MG) e implicaçóes ambientais. Revista Brasileira de Geociências, 39:151-159.

Rubio, B.; Nombela, M.A.; Vilas, F. 2000. Elements in sediments of the Ria de Vigo (NW Spain): an assessment of metal pollution. Marine Pollution Bulletin, 40:968-980.

Sahuquillo, A.; Lopez-Sanchez, J.F.; Rubio, R.; Rauret, G.; Thomas, R. P.; Davidson, C.M.; Ure, A.M. 1999. Use of a certified reference material for extractable trace metals to assess sources of uncertainty in the BCR three-stage sequential extraction procedure. Analytica Chimica Acta, 382:317-327.

Sahuquillo, A.; Rauret, G.; Rehnert A.; Muntau, H. 2003. Solid sample graphite furnace atomic absorption spectroscopy for supporting arsenic determination in sediments following a sequential extraction procedure. Analytica Chimica Acta, 476:15-24.

Santos, J.S.; Souza, F. M.; Santos, M.L. P. 2013. Distribuição de Zn, $\mathrm{Pb}, \mathrm{Ni}, \mathrm{Cu}, \mathrm{Mn}$ e Fe nas fraçóes do sedimento superficial do Rio Cachoeira na regiáo sul da Bahia, Brasil. Química Nova, 36:230-236.

Saraiva, V. K.; Nascimento, M.R.L.; Palmieri, H.E.L.; Jacomino, V.M.F. 2009. Avaliação da Qualidade de Sedimentos - Estudo de Caso: Sub-Bacia do Ribeirão Espírito Santo, afluente do Rio São Francisco. Química Nova, 32:1995-2002.

Shelton, L. R.; Capel, P. D. 1994. Guidelines for collecting and processing samples of stream bed sediments for analysis of trace elements and organic contaminants for the National Water-Quality Assessment Program, USGS, Open-File Report 94-458. 2014. (http://pubs.usgs.gov/ of/1994/0458/report.pdf). Acesso em 20/08/2014. 
Shikazono, N.; Tatewaki, K.; Mohiuddin, K. M.; Nakano T.; Zakir, H. M. 2012. Sources, spatial variation, and speciation of heavy metals in sediments of the Tamagawa River in Central Japan. Environmental Geochemistry and Health, 34:13-26.

Silva, D. L.; Lima, W. N. 1999. Utilização de matérias geológicas como agentes depuradores de aguas residuárias. Parte I - caracterização químico-mineralógica. Anais da Associação Brasileira de Química, 48:46-52.

Siqueira, G.; Aprile, F. 2013. Avaliação de risco ambiental por contaminação metálica e material orgânico em sedimentos da bacia do Rio Aurá, Região Metropolitana de Belém - PA. Acta Amazonica, 43:53-64.

Sousa, J. B.; Souza, C. A. 2012. Caracterização morfológica e mineralógica de solos em ambientes de cordilheira e campo de inundação no pantanal de Poconé, Mato Grosso. Boletim de Geografia, 31:53-66.

Thomas, R.L. 1987. A protocol for the selection of process-oriented remedial options to control in situ sediments contaminants. Ecological effects of in situ sediments contaminants. Hydrobiology, 149:247-258.

Townsend, J.M.; Rimmek, C.C; Driscoll, C.T.; Mc Farland, K.P. 2013. Mercury concentrations in tropical resident and migrant songbirds on Hispaniola. Ecotocology. 22:50-59.

Ure, A. M.; Queuvallier, Ph.; Muntau, H.; Griepink, B. 1993. Speciation of heavy metals in soils and sediments. An account of the improvement and harmonization of extraction techniques undertaken under the auspices of the BCR of the Commission of the European Communities. International Journal of Environmental Chemistry, 51:135-151.
USEPA.2007.United State Environmental Protection Agency. Method 3051a: microwave assisted acid digestion of sediments, sludges, soils and oils. (http://www.epa.gov/epawaste/hazard/testmethods/ sw846/online/3_series.htm). Acesso em 27/08/2014.

Velimirović, M. B.; Prica, M. Dj.; Dalmacija, B. D.; Rončević, S. D.; Dalmacija, M. B.; Bečelić, M. Dj.; Tričković, J. S. 2011. Characterization, Availability, and Risk Assessment of the Metals in Sediment after Aging. Water, Air and Soil Pollution, 214:219-229.

Wang, H.; Wang, C.X.; Wang, Z.J. 2002. Speciation of heavy metals in surface sediment of Taihu Lake. International Journal of Environmental Chemistry, 21:430-435.

Ye, H.; Zang, S.; Xiao, H.; Zhang, L. 2015. Speciation and ecological risk of heavy metals and metalloid in the sediments of Zhalong Wetland in China. International Journal Environment. Science Technology, 12:115-124.

Yeomans, J.C.; Bremner, J.M. 1988. A rapid and precise method for routine determination of organic carbon in soil. Communication Soil Science Plant Analysis, 19:1467-1476.

Zhang G.S.; Liu, D.Y.; Wu, H.F.; Chen, L.L.; Han, Q.X. 2012. Heavy metal contamination in the marine organisms in Yantai coast, northern Yellow Sea of China. Ecotoxicology, 21:17261733.

Zheng, S.A.; Zheng, X.Q.; Chen, C. 2013. Transformation of metal speciation in purple soil as affected by waterlogging. International Journal Environment Science Technology, 10:351-358.

Recebido em 05/06/2015

Aceito em 20/10/2015 
